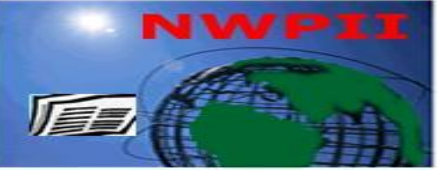

American Journal of

Biomedical Sciences

ISSN: 1937-9080

nwpii.com/ajbms

\title{
Serum Cortisol and the Risk of Osteoporosis in Nigerians on Medroxyprogesterone Acetate
}

\begin{abstract}
O. A. Popoola ${ }^{1}$, B. A. Omotosho' ${ }^{2}$ I. F. Amenkhienan ${ }^{2}$, Adedeji E. Anuoluwapo ${ }^{1}$

${ }^{1}$ Department of Medical Laboratory Sciences, College of Natural and Applied Sciences Achievers University, Owo, Ondo State, Nigeria

${ }^{2}$ Federal Medical Centre, Owo, Ondo State, Nigeria

*Corresponding Author

Olayiwola Popoola

Department of Medical Laboratory Sciences

Achievers University

Owo Ondo State

Nigeria

Tel: +2348034392762

Email: popoolaolayiwola@gmail.com

Received: 16 March 2016; | Revised: 18 May 2016; | Accepted: 28 June 2016

Abstract

Depo-Provera®; Depot-Medroxyprogesterone Acetate (DMPA) is one of the most used contraceptives and it is currently used by more than 30 million women in most of developed and developing countries. The study was designed to investigate the relationship between serum cortisol and the risk of osteoporosis in Nigerians using Depo-Provera ${ }^{\circledR}$. We investigated 50 women using Depo-Provera ${ }^{\circledR}$ and 50 age-matched control, not on DPMA. Serum cortisol, progesterone, estrogen, estradiol, serum calcium, cathepsin K and urinary excretion rate of calcium were determined in subjects and controls. Serum cortisol and cathepsin $\mathrm{K}$ were significantly higher in women using DPMA Vs controls $(\mathrm{P}<0.01)$, we also found a significantly lower estradiol, serum calcium and an increased urinary excretion rate of calcium in subjects using DPMA as compared to controls $(\mathrm{P}<0.05)$. We found a positive correlation between serum cortisol and serum calcium $(\mathrm{r}=0.553) \quad(\mathrm{P}<0.01)$, serum cortisol and cathepsin $\mathrm{K} \quad(\mathrm{r}=0.568, \mathrm{P}<0.05)$. Our study shows that hypercortisolaemia may be responsible for calcium loss, further investigation is needed to determine if cortisol induced calcium loss is responsible for bone demineralization associated with the use of DPMA.
\end{abstract}

Keywords: Medroxyprogesterone acetate, bone deminerilization, Cathepsin K, Estradiol, contraceptives, Osteoporosis. 


\section{Background}

Medroxyprogesterone acetate also known as $17 \alpha$-hydroxy- $6 \alpha$ methylprogesterone acetate, and commonly abbreviated as MDPA, is a steroidal progestin, a synthetic variant of the steroid hormone progesterone1. It is used as a contraceptive, in hormone replacement therapy and for the treatment of endometriosis as well as several other indications. It needs to be given regularly at 3-month intervals to maintain effectiveness. Sometimes the hormone may stay in the body for more than 3 months after the last injection. This can affect menstrual cycles and delay the return of fertility [1]. Most women will be fertile within 8-12 months from the last injection and there is no permanent effect on fertility [2].

One of the major adverse effects of MDPA is a reduction in bone mineral density as a result of calcium loss through urine [3]. Other side effects include Change in bleeding patterns; all women experience a change in bleeding patterns, with continued use the majority of women stop having periods and some, irregular bleeding or spotting. Heavy or continuous bleeding rarely occurs. Some women may experience weight gain as the injection may increase your appetite, headaches, breast pain and mood changes. All these symptoms can occur but they usually go away after first few weeks [1,4].

Hypercortisolemia triggers bone mineral resorption to free amino acid for use as energy source through gluconeogenesis. Cortisol exert its influence by blocking calcium absorption which decreases bone cell growth [5].

Bone mineral density (BMD) measures the quantity of calcium in grams per square centimeter an individual has in certain bones; this measurement is compared to normal BMD limits to assess the individual's risk of osteopenia and osteoporosis. The BMD loss is thought to be caused by Depo's suppression of ovarian production of estradiol, a sex hormone, which is involved in the development of bone mineral density and the attainment of peak bone mass, reducing a woman's estrogen levels may compromise BMD [6].

\section{Objectives of Study}

To determine the effects of injectable contraceptives (MDPA) on biochemical parameters that can alter bone metabolism like steroid hormones (Progesterone, estradiol and cortisol), serum calcium, urinary excretion rate of calcium and $\mathrm{pH}$ in women using this DEPOPROVERA, with a view of establishing a link between calcium loss and some biochemical parameters.

\section{Materials and Methods}

This study was carried out in the family planning unit, Community Health Center, Federal Medical Centre, Owo local government, Ondo state. This study was carried out on two groups of participants: 50 participants using injectable contraceptives and 50 age matched control participants: those not using any form of contraceptives.

Data was obtained via clinical form/questionnaires administered to participants after it has been thoroughly explained in the language the participants understood. The questionnaires cover sociodemographic details like age, height, weight, details that cover type and duration of drug use. Only participants that have been on MDPA for at least one years were recruited into the study.

Participants were made to rest and advice to avoid anything that can cause anxiety before morning cortisol samples were collected. Five millilitres of blood were collected into lithium heparin tubes from participants to determine calcium, cortisol and bicarbonate levels in serum. Timed urine samples were collected for urinary calcium estimation.

Samples collected into lithium heparin bottle were centrifuged and plasma was separated from red cell and frozen until the time for analysis. Blood samples were analyzed for cortisol, calcium and bicarbonate. Serum Calcium $(\mathrm{Ca})$ level was estimated using a modified OCPC OCresolphthalein Complexone III methodology for the quantitative determination of calcium [7], while cortisol, progesterone and estradiol were quantitatively determined using ELISA method 
using kit from DIALAB, Cathepsin $\mathrm{K}$ concentration was determined using kits manufactured by LifeSpan BioScience, Inc and bicarbonate using Ion selective electrode. Timed urine samples collected was estimated for calcium excretion rate.

Exclusion criteria: Subjects with history of thyroid dysfunction or hormonal imbalance, history of bone diseases or use of therapeutic steroids.

\section{Results and Discussion}

Tables below shows the result of physical and biochemical parameters in subjects and controls (Table 1 and 2), correlation between some biochemical parameters (Table 3). Mean plasma calcium, urinary calcium, estradiol, cathepsin $\mathrm{K}$ and cortisol have statistically significant difference when test and the control group were compared $(\mathrm{p}<0.05)$.

Table 1. Comparison of BMI, age and Waist circumference of both test and control group

\begin{tabular}{|c|c|c|c|}
\hline & TEST (Mean \pm S.D) & CONTROL (Mean \pm S.D) & P - VALUE \\
\hline BMI (kg/m $\mathbf{m}^{\mathbf{2}}$ & $26.63 \pm 2.45$ & $22.26 \pm 4.59$ & NS \\
\hline AGE (Years) & $34.38 \pm 7.06$ & $32.08 \pm 3.40$ & NS \\
\hline $\begin{array}{c}\text { Waist Circ. } \\
\text { (Inches) }\end{array}$ & $37.99 \pm 3.40$ & $34.9 \pm 2.84$ & NS \\
\hline
\end{tabular}

Table 2. Concentration of different biochemical parameters in both test and control group

\begin{tabular}{|c|c|c|c|}
\hline ANALYTE & TEST (Mean+S.D) & CONTROL (Mean+S.D) & P - VALUE \\
\hline Plasma calcium(mmol/l) & $1.78 \pm 0.44$ & $2.24 \pm 0.28$ & $<0.05^{*}$ \\
\hline Urinary calcium(mmol/l) & $1.84 \pm 0.53$ & $2.12 \pm 0.42$ & $<0.05^{*}$ \\
\hline Bicarbonate (mmol/l) & $24.89 \pm 3.72$ & $23.42 \pm 3.05$ & $<0.01^{* *}$ \\
\hline Cortisol (nmol/l) & $148.99 \pm 59.24$ & $90.83 \pm 42.19$ & $>0.05$ \\
\hline Progesterone ng/ml & $89.1 \pm 43$ & $0.71 \pm 0.55$ & $<0.01^{* *}$ \\
\hline Estradiol pg/ml & $38.65 \pm 11.31$ & $145.18 \pm 43.19$ & $<0.01^{* *}$ \\
\hline
\end{tabular}


Table 3. Showing correlation betweem cortisol and serum calcium in the test group

\begin{tabular}{|c|c|c|c|}
\hline & $\begin{array}{c}\text { Cortisol (MDPA) } \\
\mathrm{nmol} / 1\end{array}$ & $\begin{array}{c}\text { Plasma calcium (MDPA) } \\
\mathrm{mmol} / 1\end{array}$ & Cathepsin $\mathrm{K}$ pmol/l \\
\hline $\begin{array}{c}\text { Cortisol } \\
\text { Sig. (2-tailed) }\end{array}$ & 1 & $\begin{array}{c}0.553^{*} \\
0.03\end{array}$ & $\begin{array}{c}0.568 * \\
0.03\end{array}$ \\
\hline $\begin{array}{l}\text { Plasma calcium } \\
\text { Sig. (2-tailed) }\end{array}$ & $\begin{array}{c}0.553^{*} \\
0.04\end{array}$ & 1 & $\begin{array}{c}0.418 * \\
0.05\end{array}$ \\
\hline $\begin{array}{l}\text { Cathepsin K } \\
\text { Sig. (2-tailed) }\end{array}$ & $\begin{array}{c}0.568 * \\
0.03\end{array}$ & $\begin{array}{c}0.418 * \\
0.05\end{array}$ & 1 \\
\hline
\end{tabular}

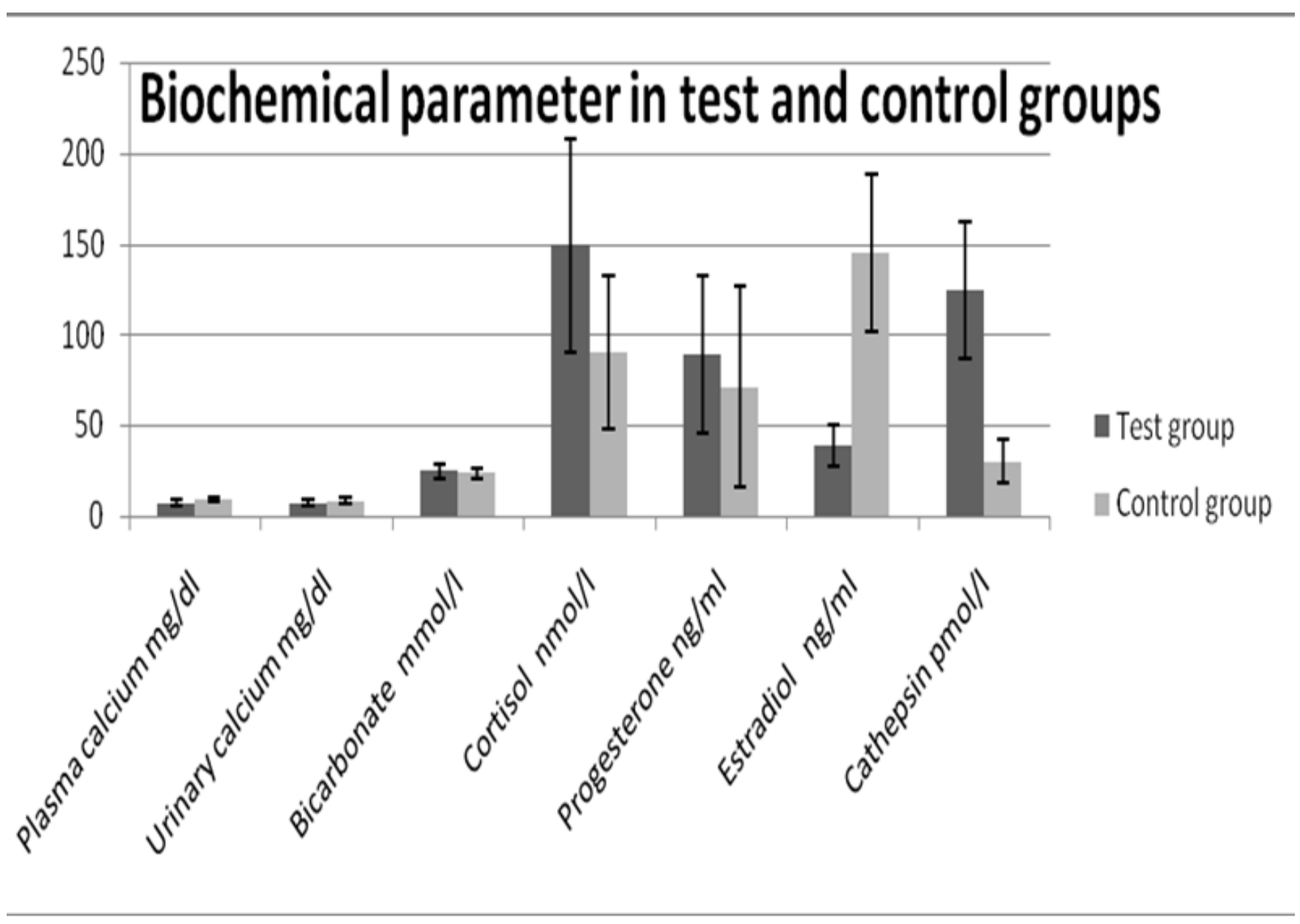

Figure 1. A line graph showing the relationship between plasma calcium, urinary calcium, bicarbonate, cortisol in the test and control groups 
The result of this study add to the growing body of evidence that cortisol is associated with bone demineralization and urinary loss of calcium. Similar studies have previously reported that decrease in bone mineral density is associated with serum cortisol in male cyclist [8], A study conducted by Dennison and colleagues reported that endogenous cortisol profile of healthy elderly men is a determinant of their bone mineral density and their rate of involutional bone loss. Elevated cortisol levels interfere with osteoblast formation and dramatically decreases bone building resulting in reduced bone density $[9,10]$. Cortisol exerts direct and indirect effects on bone, enhancing its resorption first and then inhibiting its formation [11]. Increase serum cortisol lead to a dramatic decrease in bone mineral density, either when endogenously in excess or when administered exogenously, leading to decreased intestinal calcium absorption $[3,12]$. It also induces apoptosis (programmed cell death) for osteoblast [13]. Indirectly, cortisol excess reduces the production of growth factors and bone matrix proteins and decreases calcium formation [11]. In addition to direct effects on skeletal function, glucocorticoids also decrease intestinal calcium absorption and increases urinary calcium excretion at higher doses. Thus, the net osteopenia observed in vivo after glucocorticoid treatment is probably due to a complex combination of direct effects on bone formation and resorption as well as indirect effects to inhibit intestinal calcium absorption and increase renal calcium excretion [14]. MDPA has a bioavailability of nearly $100 \%$ and no binding affinity to SHGB (Sex hormone-binding globulin) and $\mathrm{CBG}$ (corticosteroid-binding globulin) and in serum MDPA is bound to albumin for $88 \%$. The most important metabolic steps are hydroxylation reactions. The various biological effects are; positive for progestogenic, anti-gonadotrophic, anti-estrogenic and glucocorticoid activities, but it is negative for estrogenic, anti-androgeic and antimineralocorticoids activities [15]. Since MDPA is a glucocorticoids (cortisol) receptor agonist, then it may increase plasma cortisol and result in reduced calcium absorption and bone demineralization. Acidity enhances osteoblastic activity, increases osteoclastic activity and may also increase bone resorption by a direct, noncellular physicochemical process, Similarly acidogenic (high-protein) diets induce calciuria [16], However, the bicarbonate wasn't statistically different in cases compare with controls probably because of the diet of the participants or compensatory mechanism of the acid-base balance [17].

Cathepsin $\mathrm{K}$ is expressed and secreted by osteoclasts during active bone resorption, circulating form of cathepsin $\mathrm{K}$, is a useful and specific biochemical marker of osteoclastic activity of the bone tissue [18]. Our study shows a statistically significant increase in the concentration of Cathepsin $\mathrm{K}$ (Table 2) in women on MDPA versus controls, we attribute the increase in cathepsin $\mathrm{K}$ to the increase in osteoclastic activity occurring in this group of subjects. Our study further shows an association between cortisol and cathepsin K (Table 3) concentration which support our hypothesis that hypercortisolemia further exacerbates bone resorption in women taking medroxyprogesterone acetate. Estrogen hormone family plays a fundamental role in skeletal growth and homeostasis. In addition, to its use to prevent postmenopausal bone loss. Research during the last decade has revealed that estrogen regulates bone homeostasis through unexpected regulatory effects on the immune system and on oxidative stress and direct effects on bone cells [19], unfortunatule this study didn't explore a possible effect of the immune system and reactive oxygen species. Our data shows an increase in progesterone concentration in the study group (Table 2) which may likely be due to the MDPA intake or as a compensatory mechanism to stimulate bone remodelling [20]. We however, recorded a decreased concentration of estradiol, perhaps this reduction is due to anti-estrogenic effect of cortisol [15].

\section{Conclusion}

Further investigation is needed to determine if cortisol induced calcium loss is responsible for bone demineralization associated with the use of DPMA. 


\section{Acknowledgement}

The author would like to thank all academic staff members of the department of Medical Laboratory Sciences, Achievers University for scrutinizing the study proposal.

\section{Ethical Approval}

All procedures performed in studies involving human participants were in accordance with the ethical standards of the institutional and/or national research committee and with the 1964 Helsinki declaration and its later amendments or comparable ethical standards. The study protocol was reviewed and approved by ethical research committee, Federal medical centre, Owo. Informed consent were sought and obtained from all participants in the study.

\section{References}

1. Peel, N., Steven, N.R., Basto, R. and Raff, J.W. "Overexpressing centriole-replication proteins in vivo induces centriole overduplication and de novo formation. Current Biology, 2007; 17(10): 834-843. DOI: 10.1016/j.cub.2007.04.036

2. Levy, K.N., Meehan, K.B., Kelly, K.M., Reynoso, J.S., Clarkin, J.F. and Kernberg, O.F.. "Change in attachment patterns and reflective function in a randomized control trial of transference-focused psychotherapy for borderline personality disorder". Journal of Consulting and Clinical Psychology, 2006; 74(1):1027-1040.

http://dx.doi.org/10.1037/0022006X.74.6.1027

3. Lane, N.E. "An update on glucocorticoidinduced osteoporosis". Rheumatic Disease Clinics of North America, 2001;27(2):235253.

4. Bakry, S., Merhi, Z.O. and Scalise, T.J.. "Depot-medroxyprogesterone Acetate" an update. Arch Gynecol Obstet. 2008 Jul;278(1):1-12. DOI:10.1007/s00404-0070497-Z.
5. Shannon L. Mathis, Richard S. Farley, Dana K. Fuller, Amy E. Jetton, and Jennifer L. Caputo, "The Relationship between Cortisol and Bone Mineral Density in Competitive Male Cyclists," Journal of Sports Medicine, vol. 2013, Article ID 896821, 7 pages, 2013. DOI:10.1155/2013/896821

6. Clark, M.K., Sowers, M. and Levy, B.. "Bone mineral density loss and recovery during 48 months in first-time users of depot medroxyprogesterone acetate" Fertility and Sterility, 2006; 86(5):1466-1474. DOI: http://dx.doi.org/10.1016/j.fertnstert.20 06.05.024.

7. Hokazono E, Osawa S, Nakano T, Kawamoto Y, Oguchi Y, Hotta T, Kayamori Y, Kang D, Cho Y, Shiba K, Sato K. "Development of a new measurement method for serum calcium with chlorophosphonazo-III". Ann Clin Biochem. 2009 Jul; 46(Pt 4) 296-301. DOI: 10.1258/acb.2009.008099

8. Mathis, S. L., Farley, R. S., Fuller, D. K., Jetton, A. E., \& Caputo, J. L. (2013). The Relationship between Cortisol and Bone Mineral Density in Competitive Male Cyclists. Journal of Sports Medicine, 2013,896821. DOI:org/10.1155/2013/896821

9. Pereira, R.M., Delany, A.M. and Canalis, E.. "Cortisol Inhibits the Differentiation and Apoptopsis of Oesteoblasts in culture". Bone, 2001; 28(5):484-490.

10. Kim H-J, Zhao H, Kitaura $\mathrm{H}$, et al. Glucocorticoids suppress bone formation via the osteoclast. The Journal of Clinical Investigation. 2006;116(8):2152-2160. DOI:10.1172/JCI28084.

11. Chiodini, I. and Scillitani, A.. "Role of Cortisol hypersecretion in the pathogenesis of oesteoporosis". Recenti Progressi in Medicina, 2008; 99(6):309-315. DOI: $\underline{10.1701 / 364.4247}$

12. Kumar, R.. "Glucocorticoid-induced osteoporosis". Current Opinion in Nephrology and Hypertension, 2001; 10(1):589-595.

13. Hardy, R. and Cooper, M.S.. "Adrenal gland and Bone". Archives of Biochemixtry and 
Biophysics, 2010; 502(1):137-145. DOI: 10.1016/j.abb.2010.06.007

14. Briot K, Roux C. Glucocorticoid-induced osteoporosis. RMD

Open.

2015;1(1):e000014. DOI:10.1136/rmdopen2014-000014.

15. Schindler A E, Campagnoli C, Druckmann R, Huber J, Pasqualini J R, Schweppe K W, Thijssen $\mathrm{J} \quad \mathrm{H}$. Classification and pharmacology of progestins. Maturitas. 2008;61(1-2):171-80.

16. Dawson-Hughes B, Harris SS, Palermo NJ, Castaneda-Sceppa C, Rasmussen HM, Dallal GE. Treatment with Potassium Bicarbonate Lowers Calcium Excretion and Bone Resorption in Older Men and Women. The Journal of Clinical Endocrinology and Metabolism.2009;94(1):96-102.

DOI:10.1210/jc.
17. Robey, I.F. "Examining the relationship between diet-induced acidosis and cancer". Journal of Nutrition and Metabolism (London), 2012; $\quad 9(1): 72$. DOI: 10.1186/1743-7075-9-72.

18. Seibel, Markus J. "Biochemical Markers of Bone Turnover Part I: Biochemistry and Variability." The Clinical biochemist. Reviews / Australian Association of Clinical Biochemists. 26.4 (2005): 97-122. Print.

19. Weitzmann, M. Neale, and Roberto Pacifici. "Estrogen Deficiency and Bone Loss: An Inflammatory Tale." Journal of Clinical Investigation $116.5 \quad$ (2006): 11861194 DOI: $10.1172 / \mathrm{JCI} 28550$.

20. Seifert-Klauss V, Prior JC. Progesterone and Bone: Actions Promoting Bone Health in Women. Journal of Osteoporosis. 2010;2010:845180.

DOI: $10.4061 / 2010 / 845180$. 